\title{
Fet, feit eller bare overvektig?
}

BAKGRUNN Det kan være utfordrende å drøfte fedme med pasienten uten at dette oppleves som krenkende. Forebygging av livsstilssykdommer gjør det påkrevd å ta opp temaet overfor dem dette gjelder. I denne studien undersøkes pasienters uttrykkssensitivitet, det vil si hvor passende eller upassende de opplever ulike uttrykk for fedme, og hvilke pasientkarakteristika som er knyttet til uttrykkssensitivitet.

MATERIALE OG METODE Undersøkelsen er del av en femårig studie med pasienter i MidtNorge som ble behandlet for sykelig fedme. Uttrykkene i studien var foreslått av Overvektsforeningen. Data om uttrykkssensitivitet ble innsamlet ved hjelp av et spørreskjema ett år etter behandling.

RESULTATER Av 206 deltakere returnerte 157 spørreskjemaet. Gjennomsnittlig kroppsmasseindeks (BMI) (SD) var $37,6 \mathrm{~kg} / \mathrm{m}^{2}\left(7,3 \mathrm{~kg} / \mathrm{m}^{2}\right)$. Uttrykkssensitiviteten overfor 14 ulike betegnelser varierte. «Vekt», «overvekt» og «vektproblem» kom best ut, mens «obesitas», «fet» og «feit» ble vurdert som mest upassende. Mest uttrykkssensitive var kvinner, de som utviklet overvekt tidlig i livet, de med høyere utdanning og de som ikke var tilfreds med vekten.

FORTOLKNING Det var stor variasjon i hvordan ulike uttrykk for overvekt og fedme ble oppfattet. Kunnskap om temaet kan være relevant for leger og annet helsepersonell i forebygging og behandling av fedme.

Overvekt er i dagligtale ofte synonymt med både overvekt og fedme, to tilstander som skiller seg med hensyn til etiologi, prognose og behandling. Klinikere bruker gjerne WHOs klassifisering av kroppsmasse basert på kroppsmasseindeks (Body Mass Index, BMI) og nyanserer mellom overvekt og varierende grader av fedme (1). I møte med pasienter kan presise uttrykk være utfordrende, og det kan tenkes at ordbruken kan ha betydning for samarbeidsklima og behandlingsutfall.

Mange med overvekt og fedme innser at de løper en risiko for å utvikle sykdom. Like fullt er livsstilsendring vanskelig for noen. Siden $66 \%$ av befolkningen går årlig til lege, kan fastlegen spille en nøkkelrolle (2). En amerikansk studie viste at pasienter med høy kroppsmasseindeks oftere avbestiller legetimen hvis veiing inngår (3). Fra legens side er komorbiditet snarere enn kroppsmasseindeks avgjørende for om vekt tematiseres (4-6). Det kan være en negativ sammenheng mellom pasientens kroppsmasseindeks og legens bruk av tid til konsultasjonen (7). I sum kan dette tyde på at både pasient og lege har en tendens til å vike unna overvekt som tema, og at overvekt tematiseres først når komplikasjoner oppstår.

Hvordan man oppfatter sin egen kroppsstørrelse, varierer fra person til person. Oppfatningen varierer dessuten med livsfase, kjønn $(8,9)$ og alder $(10)$. Det er også en generell tendens til å underrapportere vekten (11). Økt prevalens av overvekt nå for tiden kan bidra til sosial normalisering av tilstanden og gjøre at færre ser på seg selv som overvektig.

Dessuten kompliseres trolig samtalen mellom lege og pasient av at ulike dagligdagse uttrykk om overvekt og fedme kan oppfattes som krenkende. Tematisering av kroppen rører ved den enkeltes selvfølelse, noe som aktualiseres ytterligere av at depresjon er utbredt blant mennesker med uttalt fedme (12). Generelt sett er samfunnets holdninger til overvekt negative, det innbefatter også helsevesenet (13). Selv om det eksisterer delte oppfatninger blant klinikere om hvordan overvekt bør omtales overfor pasienter $(14,15)$, foreligger det lite empiri på området. I to amerikanske studier er pasienters uttrykkssensitivitet kartlagt (16, 17), men forskjeller i språk og kultur gir liten overføringsverdi til norske forhold. Det er ingen norske studier på feltet.

I denne studien har vi undersøkt hvordan norske pasienter opplevde ulike fedmeuttrykk. Dette omtales som uttrykkssensitivitet, her forstått som hvor passende eller upassende de opplever ulike betegnelser.

Vi forsøker å gi svar på følgende spørsmål:

- I hvilken grad har pasienter med sykelig fedme opplevd at fastlegen har tematisert deres fedme?

- Hvor upassende finner fedmepasienter bruk av ulike uttrykk?

- Er uttrykkssensitivitet relatert til bakenforliggende variabler som kjønn, alder, utdanning, samlivsstatus, mental helse, vurdering av egen vekt og/eller når i livet man utviklet overvekt?

\section{Materiale og metode}

Deltakere

Analysen av uttrykkssensitivitet var et sekundært endepunkt $i$ en femårig studie

\section{Magnus Strømmen}

magnus.strommen@stolav.no

Institutt for nevromedisin

Det medisinske fakultet

Norges teknisk-naturvitenskapelige universitet og

Senter for fedmeforskning

Kirurgisk klinikk

St. Olavs hospital

Inger Johanne Bakken

Institutt for nevromedisin

Det medisinske fakultet

Norges teknisk-naturvitenskapelige universitet

\section{Ellen Andenæs}

Institutt for språk og litteratur

Det humanistiske fakultet

Norges teknisk-naturvitenskapelige universitet

\section{Christian A. Klöckner}

Psykologisk institutt

Fakultet for samfunnsvitenskap

og teknologiledelse

Norges teknisk-naturvitenskapelige universitet og

Senter for fedmeforskning

Kirurgisk klinikk

St. Olavs hospital

\section{Ronald Mårvik}

Senter for fedmeforskning

Kirurgisk klinikk

St. Olavs hospital

og

Nasjonalt senter for avansert laparoskopisk kirurgi

Kirurgisk klinikk

St. Olavs hospital

\section{Bård Kulseng}

Senter for fedmeforskning

Kirurgisk klinikk

St. Olavs hospital

\section{Are Holen}

Institutt for nevromedisin

Det medisinske fakultet

Norges teknisk-naturvitenskapelige universitet og

Smertesenteret

St. Olavs hospital

Itrate

Engelsk oversettelse på www.tidsskriftet.no

\section{HOVEDBUDSKAP}

De fleste av pasientene mente at det var riktig av legen å ta initiativ til en samtale om fedme og dens helsemessige konsekvenser

Uttrykk som obesitas, fet og feit ble opplevd som upassende, vekt og overvekt ble vurdert som mer passende

Spesielt følsomme for uttrykkene var kvinner, personer med høyere utdanning og de som utviklet overvekt tidlig i livet 
med pasienter som opprinnelig var henvist til St. Olavs hospital for behandling av sykelig fedme. Av 206 deltakere returnerte 157 spørreskjemaet (svarrate 76\%). Skjemaet ble tilsendt i forkant av ettårsundersøkelsen med oppfordring om å returnere det ved oppmøtet, hvorpå det forelå komplette opplysninger hos 142 pasienter fra Midt-Norge. Grunnet suksessiv inklusjon strakte studien seg fra 2005 til 2013. I en tidligere artikkel beskrives behandlingen pasientene gjennomgikk og de helsemessige effekter av den (18). Alle pasientene oppfylte kriteriet for sykelig fedme og hadde ved inklusjonstidspunktet BMI $>35 \mathrm{~kg} / \mathrm{m}^{2}$.

Studien er godkjent av regional etisk komité (REK) Midt-Norge.

Data

Følgende variabler inngikk $\mathrm{i}$ analysen av uttrykkssensitivitet: kjønn, alder (kontinuerlig variabel), utdanningsnivå (grunnskole/ yrkesskole eller videregående skole/høyere utdanning), samlivsstatus (aleneboende eller samboende), tidspunkt for overvektsdebut (barndom/ungdomstid eller voksen alder) og tilfredshet med vekttapet etter behandling (tilfreds eller utilfreds).

Videre inngikk dimensjonen sosial funksjonsevne fra SF-36, basert på spørsmålene om hvorvidt fysisk helsetilstand eller følelsesmessige problemer har påvirket ens sosiale omgang. SF-36 er et generisk livskvalitetsinstrument bestående av 36 spørsmål som gir grunnlag for åtte ulike erfaringsdimensjoner (19).

Vi anvendte symptomintensitet for angst målt med HADS (Hospital Anxiety and Depression Scale) (20). Både SF-36 og HADS (angstdimensjonen) inngikk i analysen som kontinuerlige variabler. Kun angstdimensjonen fra HADS ble tatt inn i regresjonsanalysen på grunn av multikollinearitet mellom denne og depresjon.

Grunnlaget for utvalget av variabler til analysen var hva vi hypotetisk antok kunne spille inn. Variabeltilfanget var også prisgitt rammene av de opprinnelige data i den femårige (hoved)studien som uttrykksstudien utgikk fra, siden denne delen av studien ble integrert etter studiestart.

\section{Uttrykkssensitivitet}

Spørsmålene om uttrykkssensitivitet var inspirert av en amerikansk studie (16). Skjemaet ble utviklet for denne studien, og testretest-analyse av 33 personer viste høy korrelasjon.

I skjemaet ble pasientene bedt om å se for seg følgende situasjon: «Du er hos fastlegen til ordinær kontroll. Dette skjedde før du ble henvist til sykehuset for behandling av overvekt. På eget initiativ ønsker fastlegen å snakke med deg om din overvekt og om
Tabell 1 Sosiodemografiske og antropometriske data for de 157 inkluderte pasientene, som alle hadde gjennomgått vektreduserende behandling ett år tidligere

\begin{tabular}{lc}
\hline Alder (år) - gjennomsnitt \pm SD & $42,6 \pm 9,2$ \\
Kvinner - antall (\%) & $119(75,8)$ \\
Menn - antall (\%) & $38(24,2)$ \\
Samboende/gift - antall (\%) & $96(57,0)$ \\
Utdanning tilsvarende bachelorgrad eller mer - antall $(\%)$ & $54(35,7)$ \\
Overvektsdebut i barndom/ungdomstid - antall (\%) & $108(71,5)$ \\
BMI (kg/m²) - gjennomsnitt utgangsverdi \pm SD & $45,2 \pm 5,7$ \\
BMI (kg/m²) - gjennomsnitt ett år etter behandling \pm SD & $37,6 \pm 7,3$ \\
\hline
\end{tabular}

konsekvensene dette kan ha for helsen. Du har ikke snakket med fastlegen om overvekt tidligere.»

Så fulgte 14 ulike uttrykk for overvekt eller fedme som var tenkt brukt av legen. Hvert uttrykk ble av pasienten skåret for uttrykkssensitivitet i henhold til en fempunkts skala med responsalternativer fra svart upassende (-2) til svart passende $(+2)$. Uttrykkene var innhentet fra Overvektsforeningen, som i forkant av studien ble oppfordret til å komme med betegnelser som kunne oppfattes som positive eller negative. Uttrykk som primært forekommer som skjellsord ble utelatt.

Følgende uttrykk inngikk i skjemaet, i denne rekkefølgen: «overvekt», «vektproblem», «BMI», «høy BMI», «fedme», «sykelig overvekt», «obesitas», «overflødig vekt», «for tung», «fet», «feit», «tykk», «kraftig» og «vekt».

Skjemaet inneholdt også følgende spørsmål (med svaralternativene ja/nei/vet ikke): Om legens valg av uttrykk ville ha hatt betydning for pasient-lege-relasjonen, om det er riktig av legen å initiere en samtale om

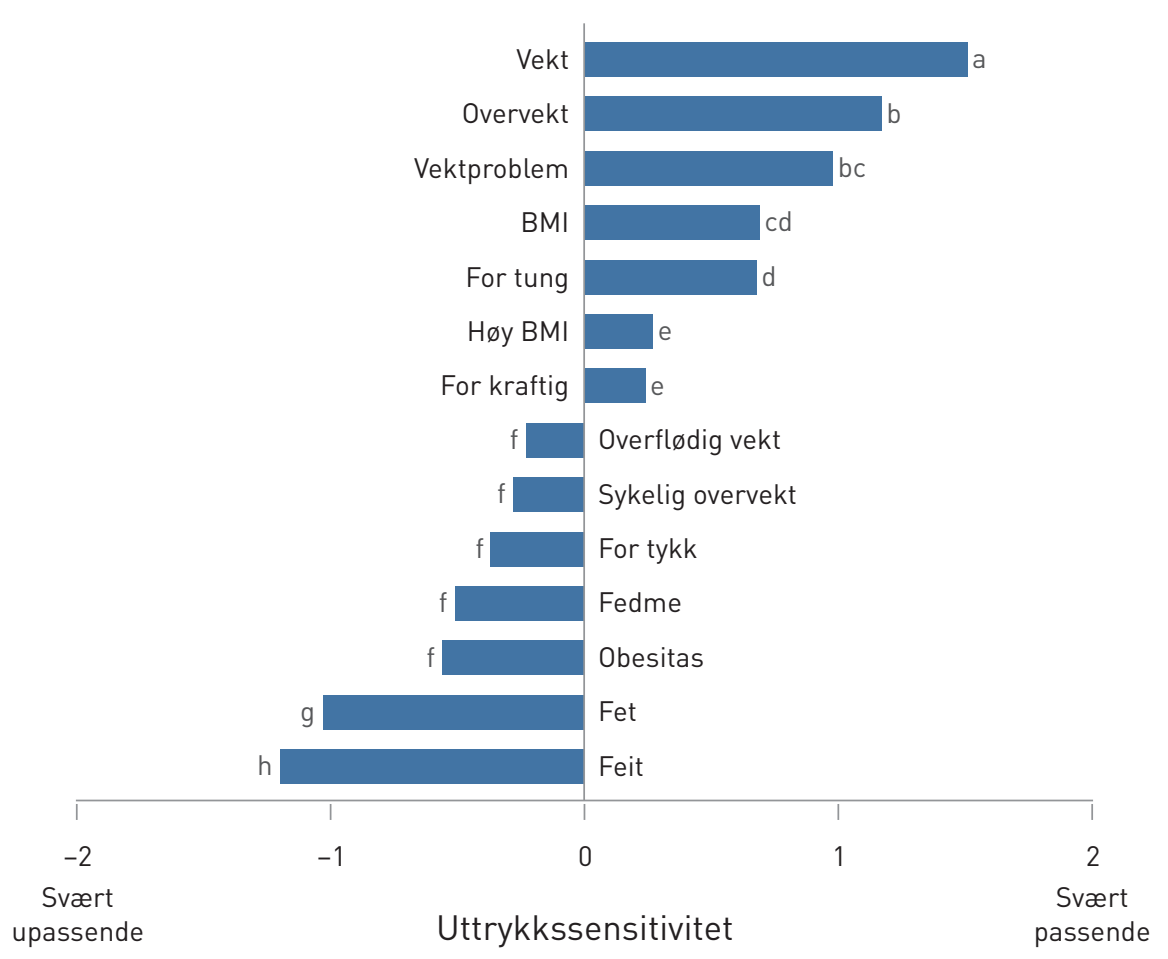

Figur 1 Uttrykkssensitivitet for 14 uttrykk for overvekt og fedme vurdert av pasienter behandlet for sykelig fedme ( $N=157)$. Søyler med ulike bokstaver er signifikant ulike ( $<<0,001)$, det vil si illustrerer uttrykk som oppleves ulikt av pasientene. Eksempel: «Vekt» oppleves forskjellig fra alle andre uttrykk, mens det er ingen forskjell mellom opplevelsen av «overvekt» og «vektproblem» 
Tabell 2 Hvem var mest sensitive for de dårligst likte fedmeuttrykkene? Multippel lineær regresjon med uttrykkssensitivitet predikert av ulike pasientkarakteristika hos $142^{1}$ pasienter som hadde gjennomgått vektreduserende behandling. $95 \%$ konfidensintervall

\begin{tabular}{lcc}
\hline & $B^{2}$ & $95 \%$ Kl av B \\
Utdanning $\left(0^{3}=\right.$ grunnskole/yrkesskole; 1 = videregående skole) & $-1,92$ & $-2,92--0,90$ \\
Fedmedebut ( 0 = barndom/ungdomstid; 1 = voksen alder) & 1,59 & $0,29-2,82$ \\
Kjønn (0 = kvinne; 1 = mann) & 1,58 & $0,39-2,86$ \\
Vurdering av egen vekt (0 = utilfreds; 1 = tilfreds) & 1,24 & $0,27-2,23$ \\
Sosial funksjonsevne (SF-36) & $-0,06$ & $-0,11-0,01$ \\
Angstsymptomer (HADS) & $-0,11$ & $-0,22-0,01$ \\
Samlivsstatus (0 = enslig; $1=$ parforhold) & 0,55 & $-0,32-1,52$ \\
Alder lår) & $-0,00$ & $-0,06-0,06$ \\
\hline
\end{tabular}

1 Fullstendige data for regresjonsanalysen kun for 142 deltakere

Beta er regresjonsvekt og utgjør forskjell i uttrykkssensitivitet når variabelen endres med én enhet mens alle andre variabler holdes konstante. Positive verdier tilsier at man er mindre uttrykkssensitiv, mens negative verdier tilsier $\emptyset$ kt sensitivitet

${ }^{3}$ For dikotome variabler er 0 referansekategorien. Eksempel: Personer med videregående skole leller mer utdanningl liker i gjennomsnitt uttrykkene nesten to poeng dårligere enn personer kun med grunnskole/ yrkesskole når de andre faktorene er like

fedme og om pasienten selv hadde opplevd at leger faktisk hadde tatt slikt initiativ.

\section{Statistiske analyser}

Uttrykkssensitiviteten kunne angis i fem kategorier. Vi benyttet Friedmans ANOVA etterfulgt av Wilcoxons signed-rank test for å vurdere forskjeller mellom uttrykkene. På grunn av et høyt antall parvise tester $(n=91)$ ble signifikansnivået justert til 0,001. De tre uttrykkene som totalt sett oppnådde den mest negative skåringen ble slått sammen til én variabel, for mer å kunne se på selve fenomenet uttrykkssensitivitet fremfor det enkelte uttrykk. En slik samlevariabel reduserer samtidig risikoen for tilfeldige målefeil.

Ved hjelp av multippel lineær regresjon undersøkte vi så om uttrykkssensitivitet var assosiert med bakenforliggende faktorer (signifikansnivå 0,05). På grunn av utvalgets begrensede størrelse gjorde vi gjentatte tilfeldige utvalg (bootstrapping), en teknikk som gir konfidensintervaller estimert av den virkelige fordelingen i materialet og ikke på en antakelse om normalfordeling. Statistiske beregninger ble utført i PASW Statistics 18 (SPSS Inc., 2009, Chicago, IL).

\section{Resultater}

Undersøkelsen er basert på 157 personer $(76,2 \%)$ som returnerte skjemaet om uttrykkssensitivitet. Ved testtidspunktet (ett år ute i studien) hadde deltakernes kroppsmasseindeks i gjennomsnitt (SD) falt fra $45,2 \mathrm{~kg} / \mathrm{m}^{2}$ $\left(5,7 \mathrm{~kg} / \mathrm{m}^{2}\right)$ til $37,6 \mathrm{~kg} / \mathrm{m}^{2}\left(7,3 \mathrm{~kg} / \mathrm{m}^{2}\right)$.

I tabell 1 vises sosiodemografiske og antropometriske data om utvalget.

\section{Pasientenes erfaringer med at legen} tematiserer overvekt og fedme

I alt mente 124 pasienter $(80 \%)$ at legens evne til å formulere seg var av betydning for samarbeidsrelasjonen, og 145 (92\%) vurderte det som riktig av legen å ta initiativ til en samtale om fedme og dens helsemessige konsekvenser. 52 pasienter (33\%) rapporterte at de hadde opplevd at legen tok slikt initiativ.

\section{Pasientenes vurdering av ord og uttrykk}

Test av den totale variasjonen mellom uttrykkene var statistisk signifikant, $\chi^{2}(13)=857,8$, $\mathrm{p}<0,001$. I figur 1 fremstilles detaljer i uttrykkssensitivitet. Av uttrykkene kom «vekt» best ut, med snittskåren (SD) 1,51 $( \pm 0,7)$ dette var signifikant forskjellig $(p<0,001)$ fra andre uttrykk. Deretter fulgte «overvekt» med 1,17 $( \pm 1,0)$, «vektproblem» med 0,98 $( \pm 1,1)$; «BMI» med $0,69( \pm 1,1)$; «for tung» med 0,68 ( $\pm 1,2)$; «høy BMI» med 0,27 $( \pm 1,2)$ og «for kraftig» med $0,24( \pm 1,2)$.

«Feit» ble vurdert som det mest upassende, med snittskår $-1,20( \pm 1,2)$. «Feit» var dessuten signifikant forskjellig fra «fet», som hadde skår $-1,03( \pm 1,2)$. Derpå fulgte fem uttrykk som innbyrdes ikke var signifikant forskjellige: «obesitas» $-0,56( \pm 1,2)$; «fedme» $-0,51( \pm 1,4)$; «for tykk» $-0,37$ $( \pm 1,3)$; «sykelig overvektig» $-0,28( \pm 1,4)$ og «overflødig vekt» $-0,23( \pm 1,3)$.

Mest uttrykkssensitive var kvinner, de som utviklet overvekt tidlig i livet, de med høyere utdanning og de som ikke var tilfreds med vekten ( $\operatorname{tab} 2$ ). Alder, samlivsstatus, angstsymptomer og sosial funksjonsevne nådde ikke signifikans i modellen. Regresjo- nen er basert på de 142 deltakerne vi hadde fullstendige data på.

\section{Diskusjon}

Studien vår viser at mange pasienter mente det er riktig at legen tar initiativ til en samtale om overvekt og fedme. Samtidig var pasientene sensitive for flere uttrykk som beskriver fedme. Mange mente at feil ordvalg påvirker relasjonen til legen negativt. Som sagt var det kvinnene som var mest uttrykkssensitive, og de som ble overvektige tidlig i livet, de med høyere utdanning og de som var utilfreds med vekten.

Hver tredje pasient rapporterte at legen tok initiativet til å snakke om fedme. Tallet er lavt når man tar deltakernes betydelige vekt $\mathrm{i}$ betraktning. En annen studie har vist at vekt var tema i kun $17 \%$ av konsultasjonene med overvektige pasienter (21). Pasienters og legers oppfatning av hvorvidt vekt $i$ det hele tatt har vært tema i konsultasjonen kan dessuten variere. I en studie fant man at pasientene langt sjeldnere enn legene mente at vekten ble omtalt. Mest avvikende oppfatning hadde pasienter som i liten grad hadde forsøkt å gå ned i vekt på egen hånd (22), hvilket understreker kompleksiteten ved å samtale om dette.

Fastleger kvier seg for å diskutere overvekt med pasienter av frykt for å støte (5, 23). Mest utfordrende er dette når legen kjenner pasienten dårlig (4). Det å lykkes med forebygging krever at temaet blir tatt opp tidlig nok. Antar man at overvektige, men ellers friske personer i mindre grad besøker fastlegen enn fete med tilleggssykdommer, betyr dette at samtalen om vekt må tas med pasienter man kjenner dårlig. Dette bør skje også i tilfeller der pasienten selv ikke tar et slikt initiativ. Funn om at komorbiditet snarere enn kroppsmasseindeks er utslagsgivende for om legen tematiserer fedme (4-6), understreker behovet for forebygging. $\mathrm{Ni}$ av ti pasienter i vår studie mente det var riktig av legen å ta et slikt initiativ.

At det er større uttrykkssensitivitet hos kvinner, kan relateres til kjønnsforskjeller når det gjelder selvbilde og kroppsbevissthet. Kvinner er mer kritiske til sin egen kropp $(8,9)$, mens menn i større grad underestimerer vekten $\sin (24)$. Det er også vist at menn foretrekker et mer direkte språk enn kvinner gjør (25).

En medvirkende årsak til økt sensitivitet hos dem med høyere utdanning kan være at de, i motsetning til personer med lavere utdanning, i mindre grad underestimerer egen vekt (24). Derfor kan det være at uttrykk i større grad oppleves som treffende. Et språksosiologisk perspektiv på dette funnet kan være at direkte språkbruk er mer utbredt i miljøer med lavere utdanning og at de med høyere utdanning derfor mangler en viss her- 
ding. En tredje forklaring på hvorfor de med høyere utdanning relativt sett synes overvekt er mer belastende, er opplevelsen av å falle utenfor sosialt aksepterte normer (26).

Noe uventet fant vi ingen prediktiv verdi av angstsymptomer målt med HADS-skalaen. Det samme gjaldt for sosial funksjonsevne, alder og samlivsstatus.

Det var klar sammenheng mellom det å være overvektig tidlig i livet og uttrykkssensitivitet. Dette kan trolig føres tilbake til erfaringer med stigmatisering på grunn av overvekt (27), noe som dermed kan ha fătt en formende innflytelse på identitetsutviklingen. Mennesker som utvikler overvekt i voksen alder internaliserer neppe samfunnets holdninger med samme styrke.

Data var innsamlet ved ettårsoppfølgingen etter fedmebehandling. Pasientene opplyste da om graden av tilfredshet med egen vekt/vekttap på det tidspunktet. Initiale vekttap kan være oppmuntrende og styrke pasientens selvbilde, noe som delvis kan forklare hvorfor de som var misfornøyd med vekten, var mer uttrykkssensitive.

Tradisjonelt har leger aktivt forvaltet utviklingen av fagterminologien (28), og klinikere tilstreber gjerne språklig presisjon. Våre funn viser imidlertid at uttrykk som for klinikere burde ha en klar denotasjon til $\mathrm{BMI}>30 \mathrm{~kg} / \mathrm{m}^{2}$, vekker negative reaksjoner hos pasientene.

Mens «overvekt/overvektig» er presise uttrykk for en kroppsmasseindeks på 25-30 $\mathrm{kg} / \mathrm{m}^{2}$, vil det være korrekt å bruke betegnelser som «fedme/fet/feit», «adipositas/adipøs» og «obesitas» ved BMI $>30 \mathrm{~kg} / \mathrm{m}^{2}$. Klinikere unngår trolig uttrykkene «adipositas/obesitas», da disse er fremmede for folk flest. De unngår kanskje også «fedme/fet/feit» av frykt for å støte. Snarere anvendes ukorrekte uttrykk som «overvekt» og «sykelig overvekt» også ved en BMI $>30 \mathrm{~kg} / \mathrm{m}^{2}$. Er det riktig å la pasientenes oppfatning av uttrykkene styre helsepersonellets språkbruk?

Spørsmålet kan ses i lys av protection motivation theory, hvor bekymring for egen helse tenkes ha en positiv verdi (29). Sentralt $i$ teorien er individets trusselvurdering opplevelsen av helserisiko (vulnerability) og konsekvensenes alvorlighetsgrad (severity). Det å være bekymret for helsen ses som en ressurs til endring av helseskadelig atferd. Man kan tenke seg at bruk av mer presise uttrykk har større potensial for uro.

Men teorien har en viktig forutsetning: Man skal på samme tid veilede og støtte ny atferd. Teorien legitimerer dermed ikke ukritisk bruk av uttrykk når behandlerrelasjonen enten vil opphøre eller ikke vektlegger endring av helseatferd. Isolert sett kan krenkende uttrykk virke mot sin hensikt (30). Samtidig er det studier som viser at fedmepasienter faktisk oppfatter direkte ut- trykk som mer motiverende for endring enn eufemismer $(31,32)$. Slik kan det forsvares å bruke et mer direkte, kanskje konfronterende språk overfor pasientene, iallfall når det gjelder menn.

Isolert sett vil valg av uttrykk neppe ha direkte betydning for graden av vekttap, men de kan bidra til påvirkning av tankeprosesser som er med på å fremskynde atferdsendring. Det å høre legen si at man er fet, kan få pasienten til å innse alvoret i situasjonen. En slik forståelse er også i samsvar med hva vi vet om relativ sykdomsrisiko (33).

$\mathrm{Vi}$ vet fra før at menn og yngre generelt foretrekker en mer direkte uttrykksmåte (31). Vår studie bekrefter kjønnsforskjellen, men viser også andre faktorer av betydning. Hvor grensen går mellom hva som er motiverende og hva som bare er krenkende, er vanskelig å si. Opplever pasienten å bli stigmatisert, kan reaksjoner bli unngåelse av konsultasjoner eller legebytte. Slik kan en uheldig språkbruk i verste fall ha negative helsekonsekvenser (32).

Denne studien tok utgangspunkt i pasienter med sykelig fedme. Funnene kan ikke uten videre generaliseres til den atskillig større populasjonen av overvektige som ikke er behandlingssøkende. Vi må dessuten ta $\mathrm{i}$ betraktning at et av spørsmålene var knyttet til forhold som ligger noe tilbake i tid og at det kan ha innvirket på svarene. Utvalget av variabler til regresjonsanalysen var begrenset av data innsamlet for denne delstudien ble satt i gang. Flere variabler som vi ikke hadde tilgang til, kan tenkes å påvirke uttrykkssensitiviteten og ville derfor ha kunnet påvirke resultatet.

Funnene er etter vårt syn relevante - særlig for fastleger. De ser ofte pasientens vektutvikling og har en oppgave $i$ å forebygge. Kunnskap om hvordan språkbruken oppleves, kan senke terskelen for å tematisere kroppsvekt på et tidlig tidspunkt og slik kanskje gjøre forebygging mer effektivt.

Forskningsfondet ved Unimed Innovation og St Olavs hospital har gitt økonomisk støtte til studien.

\section{Magnus Strømmen (f. 1973)}

er ph.d.-student i klinisk medisin, m.sc. og forskningssykepleier.

Forfatter har fylt ut ICMJE-skjemaet og oppgir ingen interessekonflikter.

\section{Inger Johanne Bakken (f. 1968)}

er dr.ing. innen biofysikk og medisinsk teknologi og seniorrådgiver innen registerepidemiologi ved Folkehelseinstituttet.

Forfatter har fylt ut ICMJE-skjemaet og oppgir ingen interessekonflikter.

\section{Ellen Andenæs (f. 1951)}

er førsteamanuensis i anvendt språkvitenskap leder for Seksjon for språklig kommunikasjon og koordinator for forskergruppe i helsekommunikasjon og etikk ved Norges teknisk-naturvitenskapelige universitet.

Forfatter har fylt ut ICMJE-skjemaet og oppgir ingen interessekonflikter.

\section{Christian A. Klöckner (f. 1972)}

er professor i sosialpsykologi og kvantitative metoder og metodekonsulent ved Senter for sykelig overvekt i Midt-Norge.

Forfatter har fylt ut ICMJE-skjemaet og oppgir ingen interessekonflikter.

\section{Ronald Mårvik (f. 1949)}

er spesialist i gastroenterologi og i generell kirurgi og avdelingsoverlege.

Forfatter har fylt ut ICMJE-skjemaet og oppgir ingen interessekonflikter.

\section{Bård Kulseng (f. 1951)}

er spesialist i endokrinologi, professor ved Institutt for kreftforskning og molekylær medisin og leder av Senter for fedmeforskning. Forfatter har fylt ut ICMJE-skjemaet og oppgir ingen interessekonflikter.

\section{Are Holen (f. 1945)}

er spesialist i psykiatri og professor

Forfatter har fylt ut ICMJE-skjemaet og oppgir ingen interessekonflikter.

\section{Litteratur}

1. Obesity. Preventing and managing the global epidemic. Genève: World Health Organisation, 2000.

2. Nossen JP. Hva foregår på legekontorene? Konsultasjonsstatistikk for 2006. Oslo: Arbeids- og velferdsdirektoratet, 2007

3. Olson CL, Schumaker HD, Yawn BP. Overweight women delay medical care. Arch Fam Med 1994: 3 . 888-92.

4. Kristeller JL, Hoerr RA. Physician attitudes toward managing obesity: differences among six specialty groups. Prev Med 1997; 26: 542-9.

5. Michie S. Talking to primary care patients about weight: a study of GPs and practice nurses in the UK. Psychol Health Med 2007; 12: 521-5.

6. Potter MB, Vu JD, Croughan-Minihane M. Weight management: what patients want from their primary care physicians. J Fam Pract 2001: 50: $513-8$

7. Hebl MR, Xu J. Weighing the care: physicians reactions to the size of a patient. Int J Obes Relat Metab Disord 2001: 25: 1246-52.

8. Grover VP, Keel PK, Mitchell JP. Gender differences in implicit weight identity. Int J Eat Disord 2003; 34: 125-35

9. Pingitore R, Spring B, Garfield D. Gender differences in body satisfaction. Obes Res 1997: 5: 402-9.

10. Reboussin BA. Correlates of satisfaction with body function and body appearance in middle-and older aged adults: The Activity Counseling Trial (ACT). Psychol Health 2000: 15: 239-54.

11. Niedhammer I, Bugel I, Bonenfant S et al. Validity of self-reported weight and height in the French GAZEL cohort. Int J Obes Relat Metab Disord 2000 24: 1111-8. 
12. Onyike CU, Crum RM, Lee HB et al. Is obesity associated with major depression? Results from the Third National Health and Nutrition Examination Survey. Am J Epidemiol 2003; 158: 1139-47.

13. Puhl RM, Heuer CA. The stigma of obesity: a review and update. Obesity (Silver Spring) 2009; 17: $941-64$.

14. Guide to authors. The Obesity Society http://onlinelibrary.wiley.com/journal/10.1002/ (ISSN)1930-739X/homepage/ForAuthors.html (14.9.2015).

15. Holmén J. Den som lider av fetma är fet! Läkartidningen 1999; 96: 3081

16. Volger S, Vetter ML, Dougherty M et al. Patients preferred terms for describing their excess weight: discussing obesity in clinical practice. Obesity (Silver Spring) 2012; 20: 147-50.

17. Wadden TA, Didie E. What's in a name? Patients' preferred terms for describing obesity. Obes Res 2003; 11: 1140-6.

18. Martins C, Strømmen M, Stavne OA et al. Bariatric surgery versus lifestyle interventions for morbid obesity - changes in body weight, risk factors and comorbidities at 1 year. Obes Surg 2011; 21: $841-9$.

19. Ware JE Jr. SF-36 health survey update. Spine 2000; 25: 3130-9

20. Zigmond AS, Snaith RP. The hospital anxiety and depression scale. Acta Psychiatr Scand 1983; 67: $361-70$.

21. Scott JG, Cohen D, DiCicco-Bloom B et al. Speaking of weight: how patients and primary care clinicians initiate weight loss counseling. Prev Med 2004; 38: 819-27.

22. Greiner KA, Born W, Hall S et al. Discussing weight with obese primary care patients: physician and patient perceptions. J Gen Intern Med 2008; 23 581-7.

23. Tailor A, Ogden J. Avoiding the term 'obesity': an experimental study of the impact of doctors' language on patients' beliefs. Patient Educ Couns 2009; 76: 260-4.

24. Kuchler F, Variyam JN. Mistakes were made: misperception as a barrier to reducing overweight. Int J Obes Relat Metab Disord 2003; 27: 856-61.

25. Kirtley MD, Weaver JB. Exploring the impact of gender role self-perception on communication style. Women's. Stud Commun 1999; 22: 190-209.

26. Ross CE. Overweight and depression. J Health Soc Behav 1994; 35: 63-79.

27. Latner JD, Stunkard AJ. Getting worse: the stigmatization of obese children. Obes Res 2003; 11 : 452-6.

28. Myking J. Terminologiutvikling - kulturpolitikk og sosialpolitikk. Tidsskr Nor Legeforen 2008; 128 : 850.
29. Norman P, Boer H, Seydel ER. Protection motivation theory. I: Conner M, Norman P, red. Predicting health behaviour. New York, NY: McGraw-Hill Education, 2005

30. Boer H, Seydel ER. Protection motivation theory. I: Conner M, Norman P, red. Predicting health behaviour. New York, NY: McGraw-Hill Education, behaviou.

31. Gray CM, Hunt K, Lorimer K et al. Words matter: a qualitative investigation of which weight status terms are acceptable and motivate weight loss when used by health professionals. BMC Public Health 2011; 11: 513.

32. Puhl R, Peterson JL, Luedicke J. Motivating or stigmatizing? Public perceptions of weight-related language used by health providers. Int J Obes 2013; 37: 612-9.

33. Wilson PWF, D'Agostino RB, Sullivan $L$ et al. Overweight and obesity as determinants of cardiovascular risk: the Framingham experience. Arch Intern Med 2002; 162: 1867-72.

Mottatt 27.6. 2014, første revisjon innsendt 2.12. 2014. godkjent 14.9. 2015. Redaktør: Tor Rosness. 